\title{
ASO Visual Abstract: Adrenocortical Carcinoma-The Value of Lymphadenectomy
}

Joshua Tseng, MD¹, Timothy DiPeri, MD ${ }^{1}$, Yufei Chen, MD ${ }^{1}$, Daniel Shouhed, MD ${ }^{1}$, Anat Ben-Shlomo, MD ${ }^{2}$, Miguel Burch, MD ${ }^{1}$, Edward Phillips, $\mathrm{MD}^{1}$, and Monica Jain, $\mathrm{MD}^{1}$

${ }^{1}$ Division of Minimally Invasive Surgery and Endocrine Surgery, Department of Surgery, Cedars-Sinai Medical Center, Los Angeles, CA; ${ }^{2}$ Division of Endocrinology, Diabetes and Metabolism, Adrenal Program, Cedars-Sinai Medical Center, Los Angeles, CA

Increasing quantitative metastatic lymph node burden is associated with incrementally worse survival for adrenocortical carcinoma. Regional lymphadenectomy during adrenalectomy not only allows for improved staging, but also is associated with a survival benefit (https://doi.org/ 10.1245/s10434-021-11051-5).

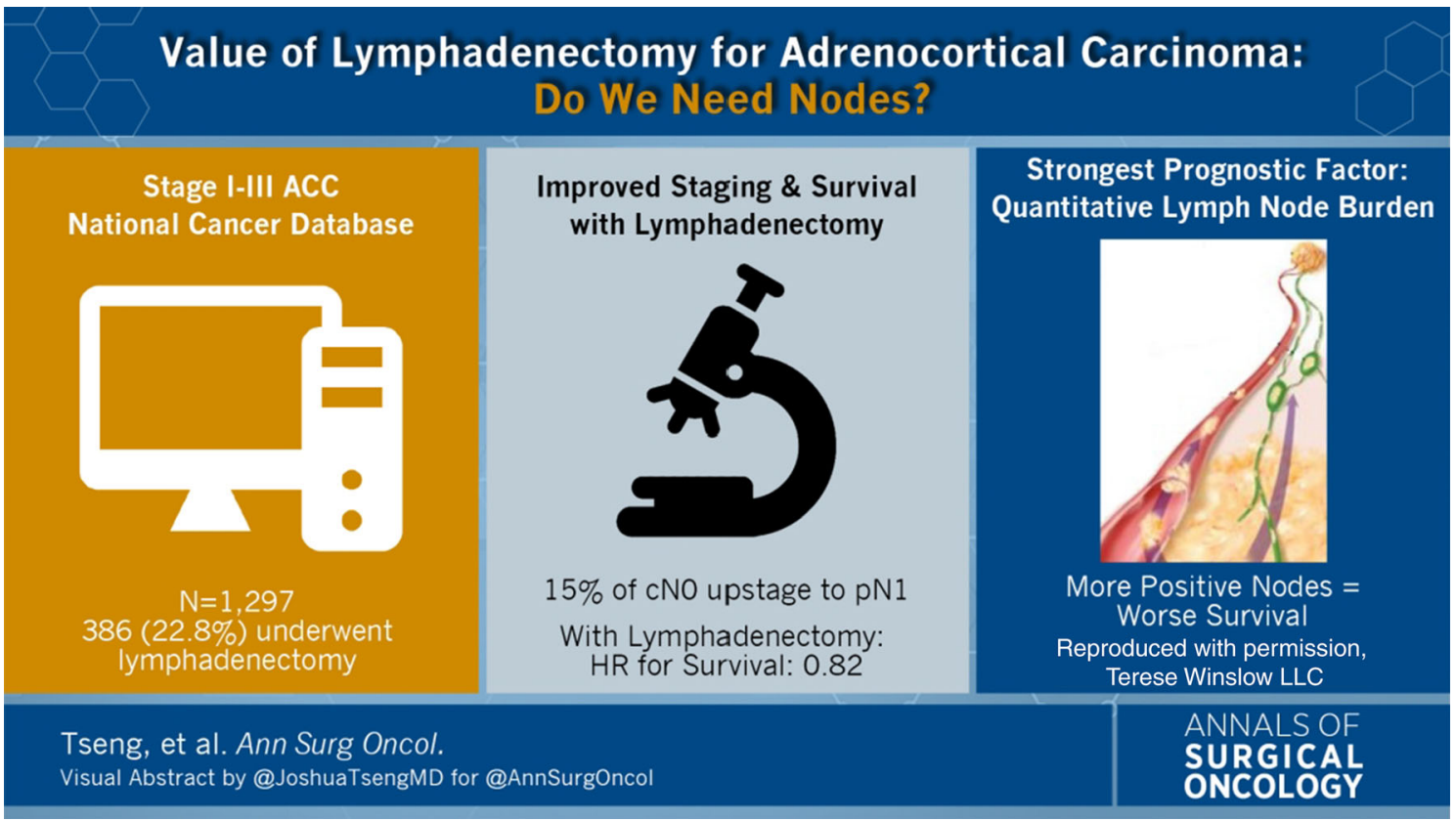

(C) Society of Surgical Oncology 2021

M. Jain, MD

e-mail: monica.jain@cshs.org

DISCLOSURES No authors have any commercial interest in the subject of the study.

Publisher's Note Springer Nature remains neutral with regard to jurisdictional claims in published maps and institutional affiliations. 